\title{
La duda fantástica o la realidad siniestra: consideraciones sobre Cecilia Hurtado y su obra
}

Lo Unheimlich (...) está próximo a lo espantable, angustiante, espeluznante, pero no es menos seguro que el término se aplique (...) a una acepción un tanto

indeterminada. Sigmund Freud (Lo siniestro, 1919)

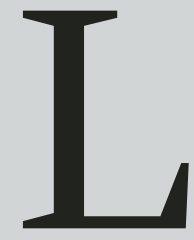

a cuestión clave en ciertas obras de arte se rige por lo sugerente, al igual que sucede con la mejor poesía. Leer la imaginería fantástica de Cecilia Hurtado - pensando en Tzvetan Todorov, que se dedicó a definir "lo extraño"- refleja ese arbitraje que debe tomar quien se ubica frente a lo estético. Experimentar la extrañeza de lo fantástico dura apenas el lapso de una vacilación. Esa duda fantástica, ese misterio retador es común para el espectador o espectadora como para los personajes de lo mirado. Un estilo que remite, sin titubeos, a esos ojos barrocos que nos hacen participar, resolver y aceptar nuevas leyes impuestas por la artista, para permanecer con esa duda extraña que logra que la obra sea interminable.

$\mathrm{Si}$, en cambio, aunque no muy lejano, optamos por una mirada a partir de aquella entrañable percepción de lo siniestro de Freud, sabemos que hay o habrá algo por detrás, por adentro. Lo Unheimlich procede de lo familiar, que ha sido reprimido y ha vuelto. Exactamente así de inquietante. Cuando estamos en presencia de quienes protagonizan estas geniales intervenciones, nos es pedido contestar un enigma: porque su mirada nos absorbe y nos cuestiona esas notas de nuestro interior. Identidad, género, raza, clase, sexo, angustia, placer, se extienden en un sentimiento que pasa -como lo haría un péndulo- desde lo íntimo, lo confidencial, lo que rememora al hogar a esa realidad nuestra que quiere salir y que sólo el mejor arte puede provocar y salvar.

Los múltiples sentidos de la obra de Cecilia Hurtado nos reciben para dejarnos pensar, permitirnos sentir y, ante todo, ser parte infinita de una serie de registros que siempre viene por más.
El desafío se queda de nuestro lado; la entrega ha sido hecha. Ahora toca animarnos.

Analhi Aguirre

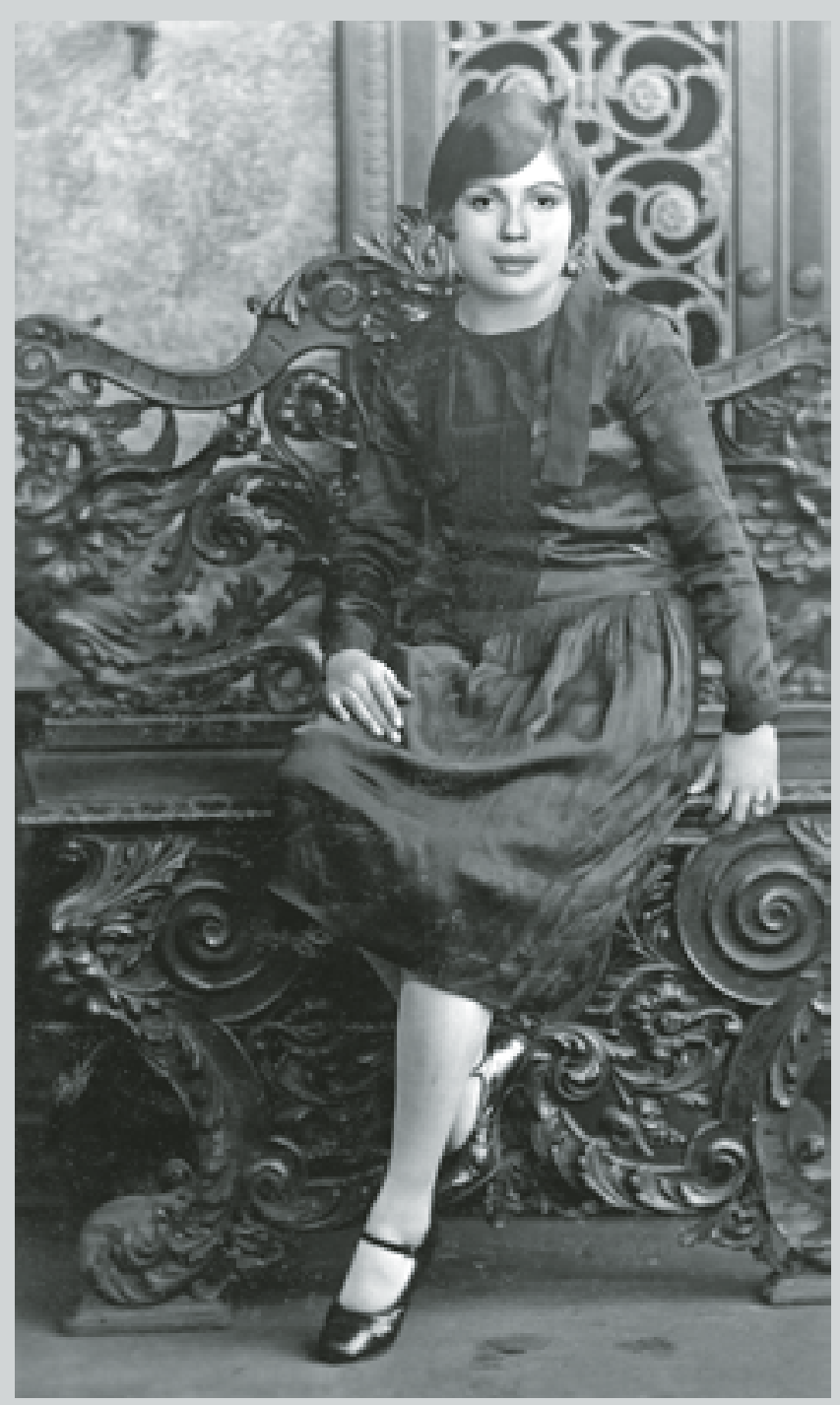




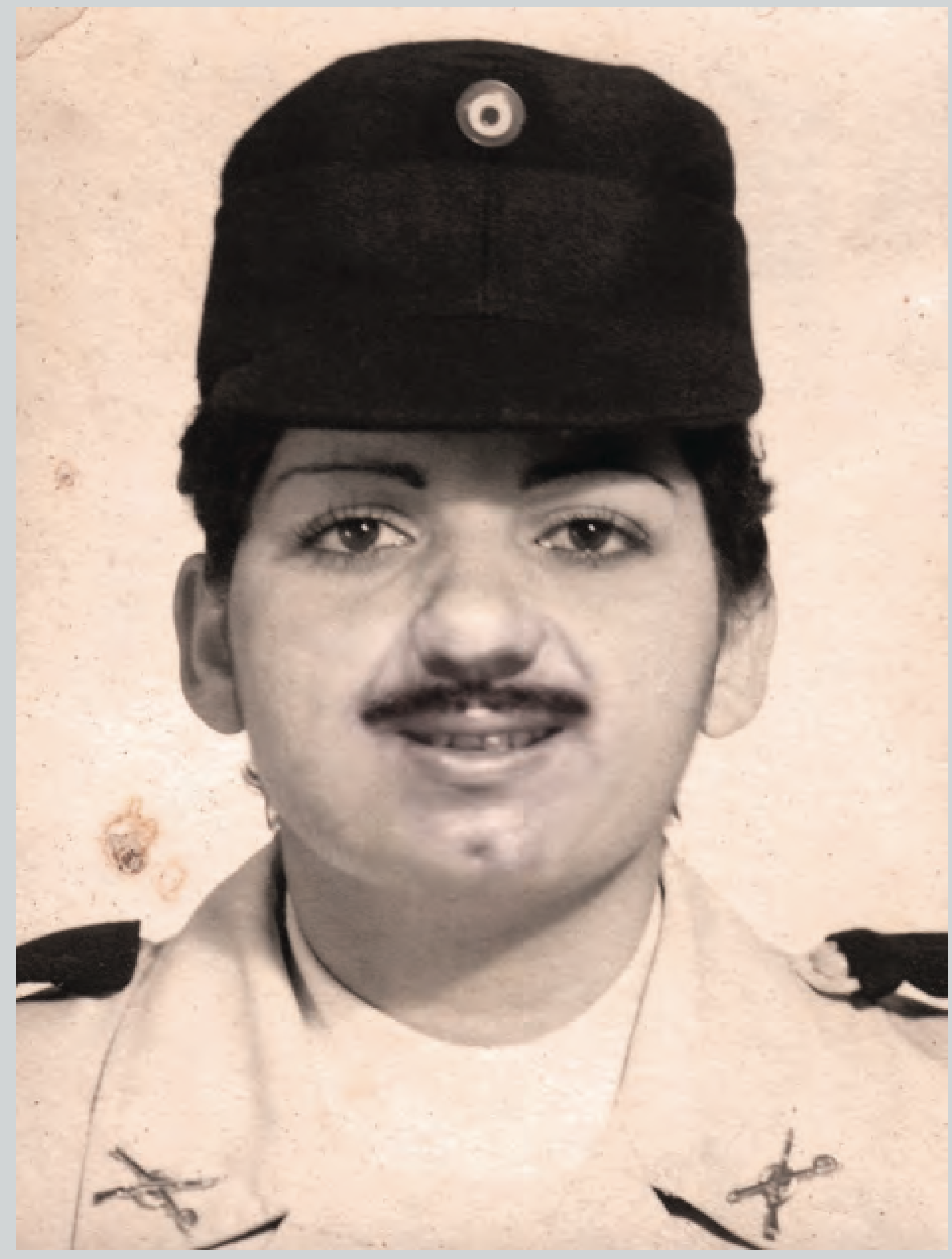




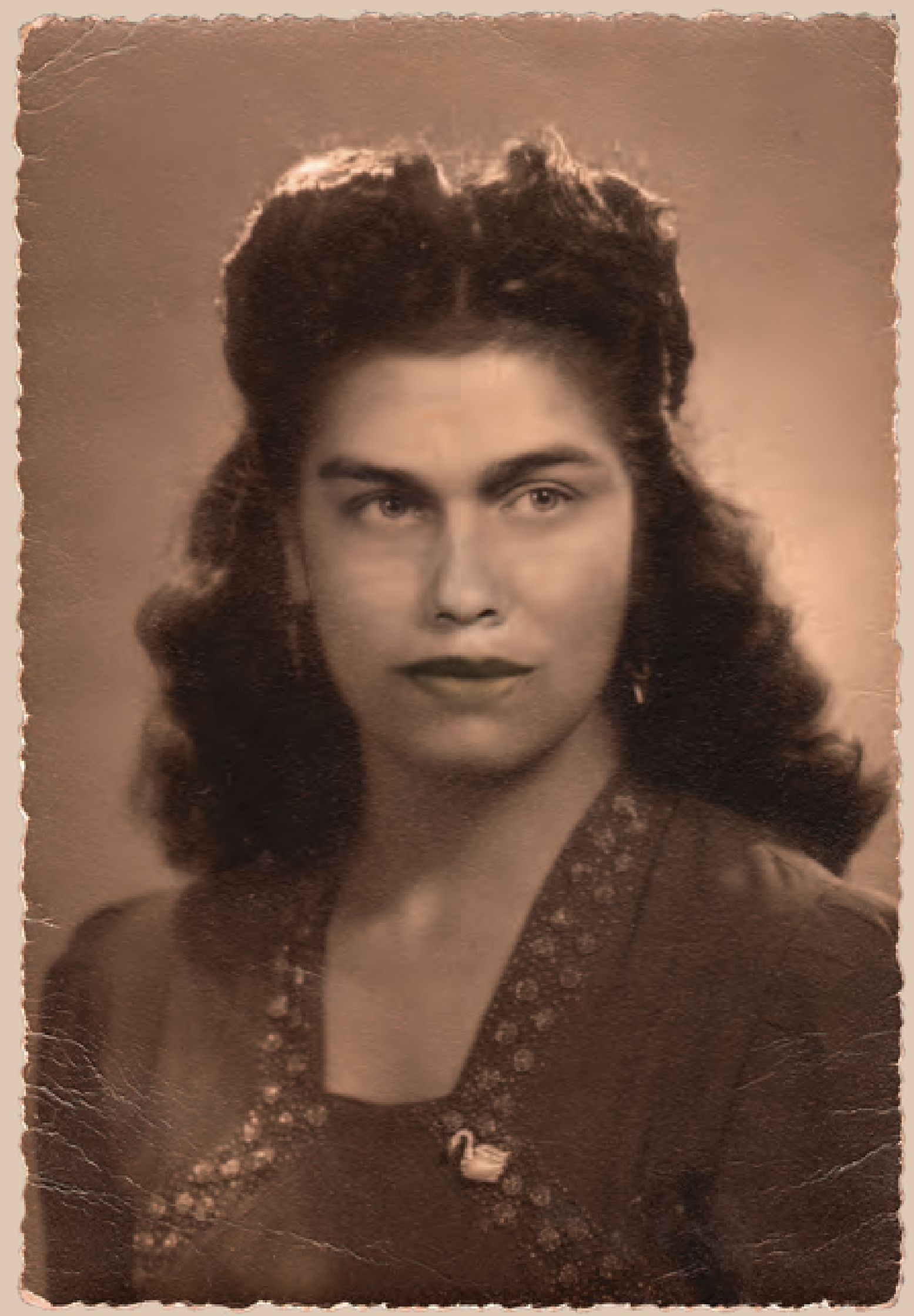




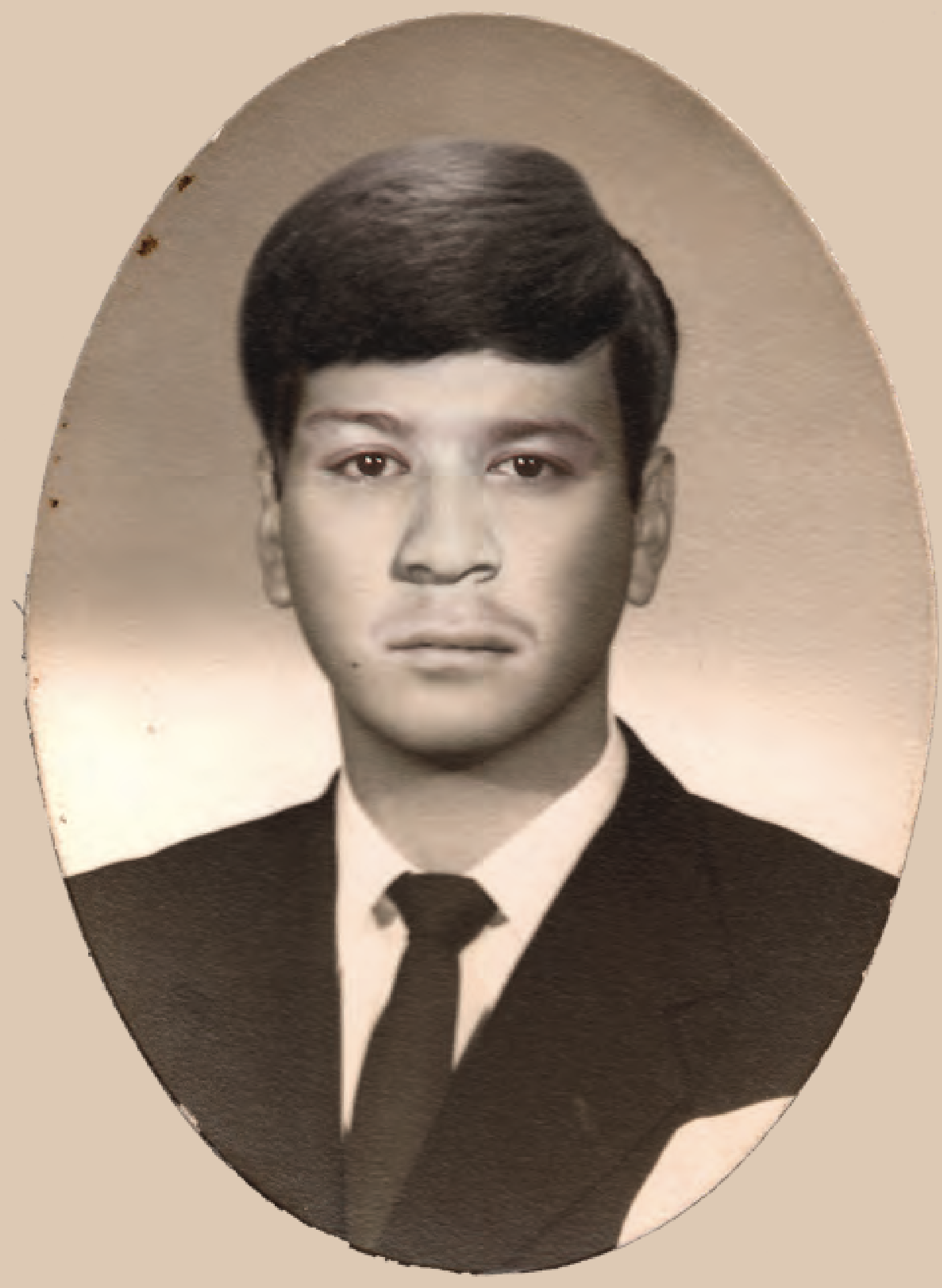




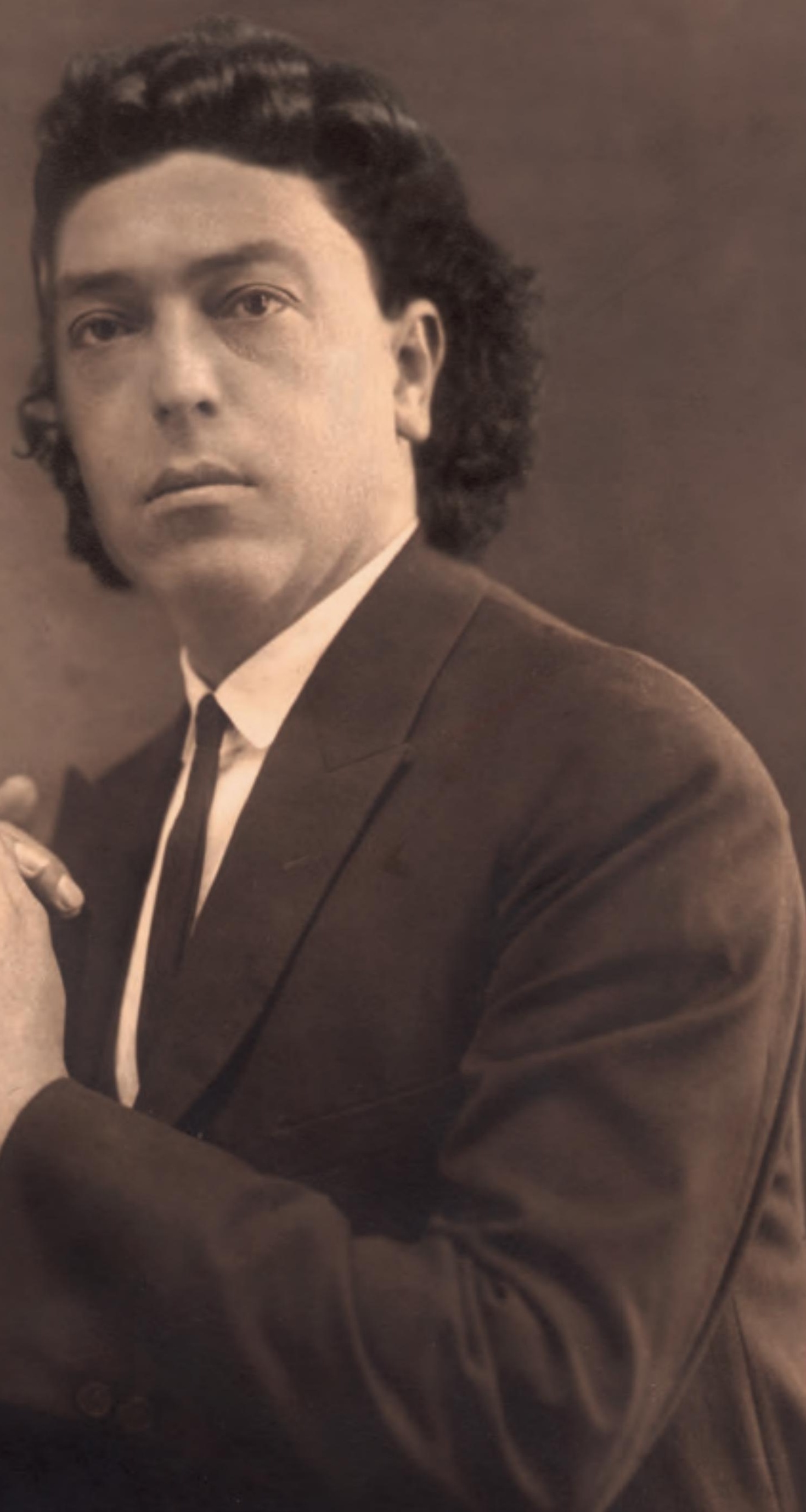




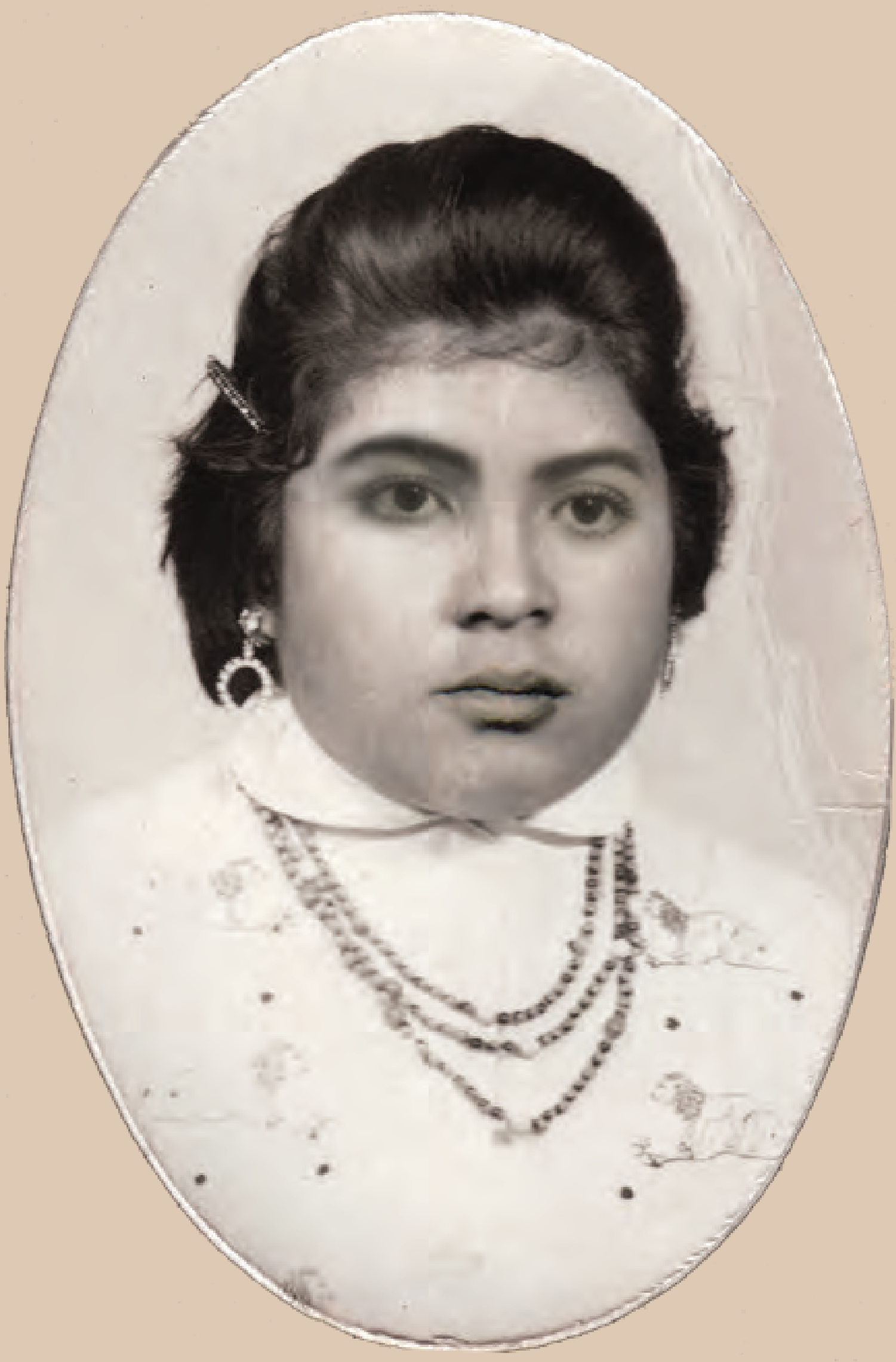




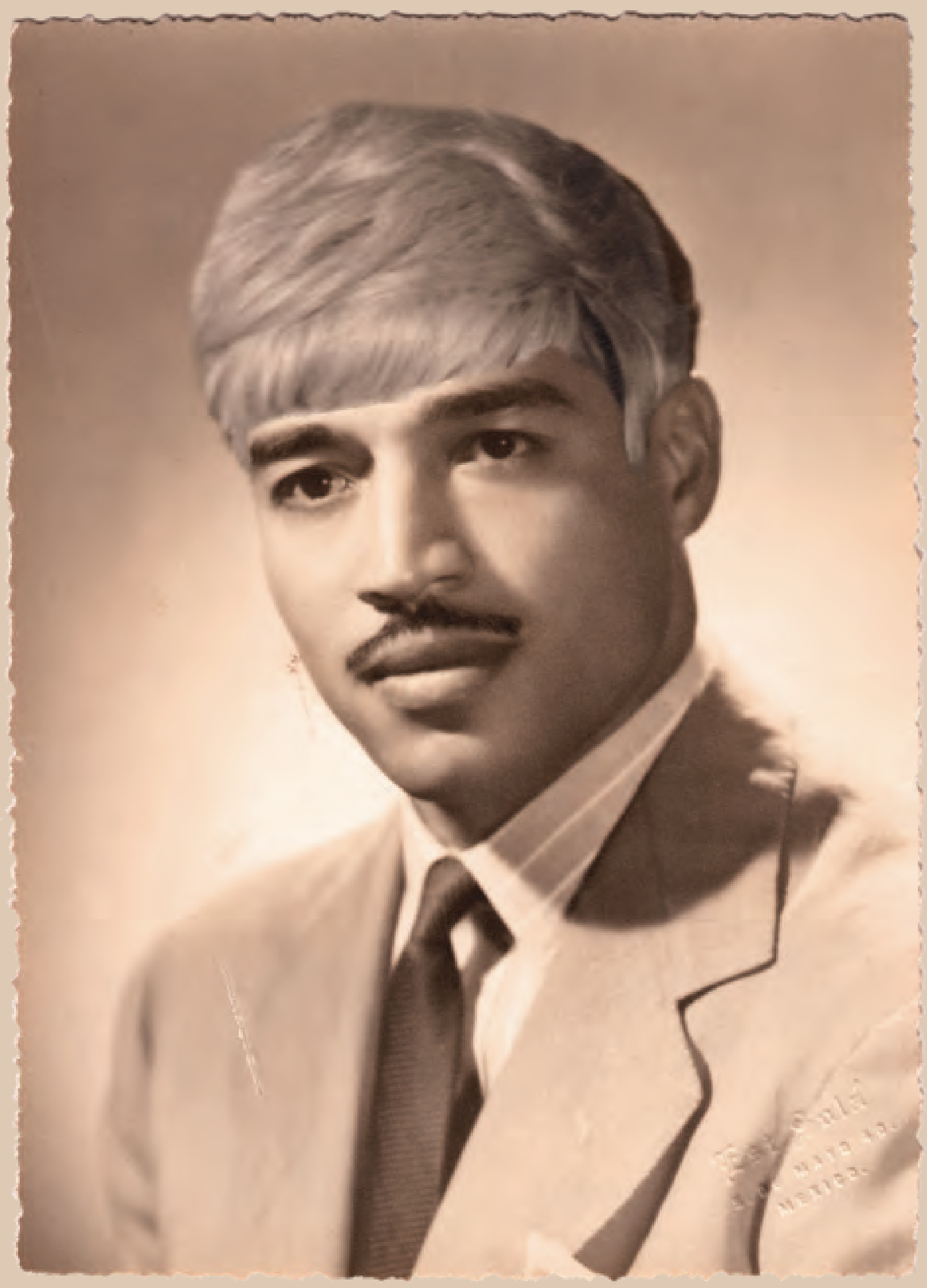




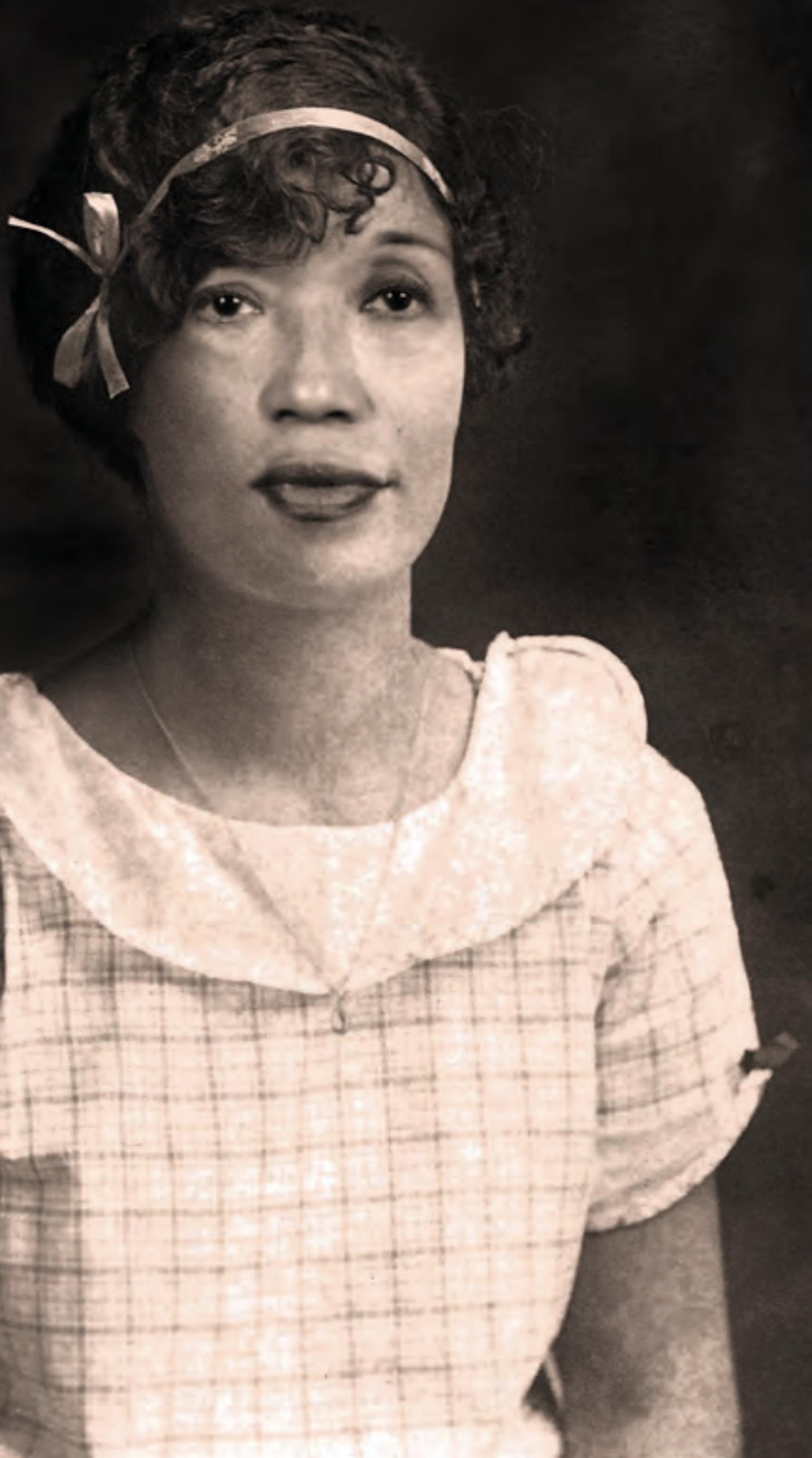

